\title{
A credit card sized self powered smart sensor node
}

\author{
Dibin Zhu*, Stephen P. Beeby, Michael J. Tudor, Nick R. Harris \\ School of Electronics and Computer Science, University of Southampton, Southampton SO17 1BJ, UK
}

\section{A R T I C L E I N F O}

\section{Article history:}

Available online $\mathrm{xxx}$

\section{Keywords:}

Vibration energy harvesting

Piezoelectric generator

Self-powered

Wireless sensor node

\begin{abstract}
A B S T R A C T
This paper reports a self powered smart sensor node (also called 'smart tag') consisting of a piezoelectric vibration energy harvester, a power conditioning circuit, sensors and an RF transmitter. The smart tag has dimensions similar to a credit card and can be easily integrated into various applications such as the surface of the aircraft. The smart tag is powered by an integrated bimorph piezoelectric generator that extracts energy from ambient vibrations. The generator is fabricated using thick film printing technology. Experimentally, the generator produced a maximum RMS output power of $240 \mu \mathrm{W}$ when excited at vibration with a frequency of $67 \mathrm{~Hz}$ and peak amplitude of $0.4 \mathrm{~g}\left(3.9 \mathrm{~m} \mathrm{~s}^{-2}\right)$. This generated power is sufficient to enable periodic sensing and transmission. Details of the experimental results of the piezoelectric generator and the power conditioning circuit are presented. Test shows that the waiting time of the system between two consecutive transmissions is around $800 \mathrm{~s}$.
\end{abstract}

(c) 2011 Elsevier B.V. All rights reserved.

\section{Introduction}

Wireless sensor networks have been of great interests over the last few decades [1]. Compared to wired systems, wireless systems can be used more widely due to their flexibility. Once deployed, wireless sensor nodes can be routed and connected without changing their physical layout. One concern about the wireless sensor nodes is their power supply. Conventional power source for wireless sensor nodes is batteries. However, replacing batteries is a tedious and costly job. Therefore, it is preferred to make the sensor nodes have the ability to generate energy from ambient environment, for example, energy harvesting from photonic, thermal and mechanical energy.

Vibration energy harvesting, as a promising solution to powering wireless sensor nodes, has been studied comprehensively over the recent years. Piezoelectric, electromagnetic, electrostatic and magnetostrictive transduction mechanisms are commonly used to convert mechanical energy into electrical energy [2]. While conventional vibration energy harvesters can only work at one fixed frequency, advanced strategies have been studied to increase the operating frequency range, offering a more extensive range of applications [3]. Among all transduction mechanisms, piezoelectric is the most common one due to its simplicity [4-7].

Although most research present standalone vibration energy harvesters, some self-powered wireless sensor systems have also been reported. James et al. [8] reported a self-powered system

\footnotetext{
* Corresponding author.

E-mail address: dz@ecs.soton.ac.uk (D. Zhu).
}

which was powered by a mechanical to electrical energy converter for condition monitoring applications. Torah et al. [9] presented a wireless sensor node powered by an electromagnetic vibration energy harvester. The node integrated an accelerometer and an AM transmitter. It could measure and transit data every $3 \mathrm{~s}$. One potentially important application of wireless sensors is Structure Health Monitoring (SHM) in aircraft [10-15]. In recent years, many self-powered systems for structural health monitoring have also been reported [16-19]. These systems were powered by various energy harvesters that produced enough energy regular measurement.

This work is part of the EU Framework 7 project TRIADE. The aim of the TRIADE project is to develop a low-profile, planar, self powered intelligent sensor device (also known as smart tag) that can be fabricated within a composite material, and thus embedded in the structure of an aircraft to monitor structural health and transmit measurement data wirelessly to the base station during the flight. As a partner of this project, researchers in University of Southampton work mainly on energy harvesting. Details of work of other partners in this project, including SHM scheme, can be found in [20].

Although our work focuses on the generator, it is useful to demonstrate its use in a real application, and this involves defining a target environment, and then using the generator to power an example sensor node. Our initial target for this generator is the vertical fin of a PZL SW4 helicopter. Due to size restrictions for this application, a thick film piezoelectric generator was selected as the power source. An initial prototype of the thick film piezoelectric generator designed for this application has already been reported [21]. The generator produced a peak power of $117 \mu \mathrm{W}$ 


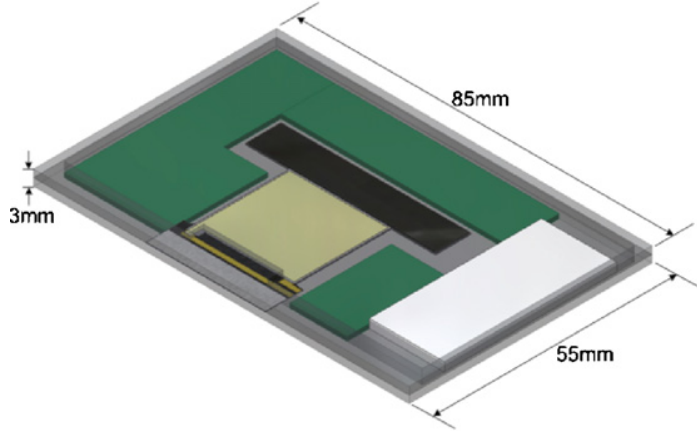

a Perspective view of the smart tag.

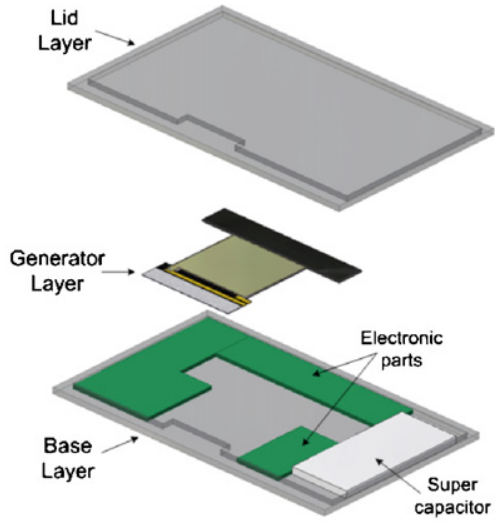

b Integration concept of the smart tag: lamination of different layers.

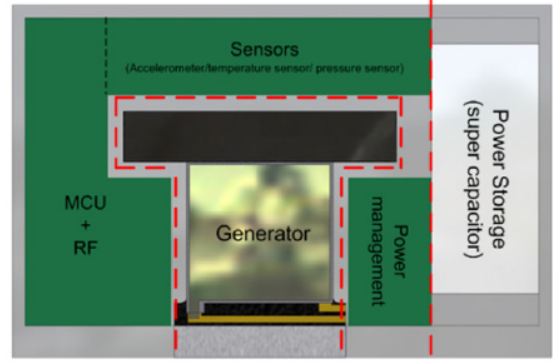

c Layout of the smart tag.

Fig. 1. Overview of the smart tag. (a) Perspective view of the smart tag. (b) Integration concept of the smart tag: lamination of different layers. (c) Layout of the smart tag.

when excited at $6.9 \mathrm{~m} \mathrm{~s}^{-2}$ (RMS) and $70 \mathrm{~Hz}$ with an optimum load of $140 \mathrm{k} \Omega$ and an output voltage of $2.9 \mathrm{~V}$, but for the target application the generator was redesigned to be active at $67 \mathrm{~Hz}$ with an expected acceleration of $2.8 \mathrm{~m} \mathrm{~s}^{-2}$ (RMS) from measured vibration spectra.

This paper describes a simple sensor node, using off the shelf sensors to demonstrate the practicality of the generator in relation to current low power systems. It should be noted that this in only an example system, and that other sensors can be designed into the system. The paper then describes the design of the thick-film generator for this application, and discusses the power conditioning and storage system needed to allow the operation of standard electronics. This results in a credit card sized self powered smart sensor node consisting of an improved piezoelectric vibration energy harvester, its power conditioning circuit, sensors and an RF transmitter. Finally, performance of the system is investigated experimentally and is discussed.

\section{Smart tag}

\subsection{Overview}

The smart tag has dimensions similar to a credit card, i.e., $85 \mathrm{~mm} \times 55 \mathrm{~mm} \times 3 \mathrm{~mm}$ (Fig. 1(a)). It consists of three layers as shown in Fig. 1(b). The lid and base layers provide protection for the smart tag, rigid clamping for the generator and contain recesses that provide the space for the generator to vibrate. Additionally, the base layer is used to mount a super-capacitor for energy storage and an electronic circuit for power management, the sensors and an RF transmitter. The piezoelectric generator is located in the middle layer which also contains space for the electronics and super-capacitor. The smart tag is divided into five areas as shown in Fig. 1(c). The piezoelectric generator is located in the centre of the tag and the super-capacitor for power storage is placed at the edge of the tag. Three PCB boards are distributed in the remain-

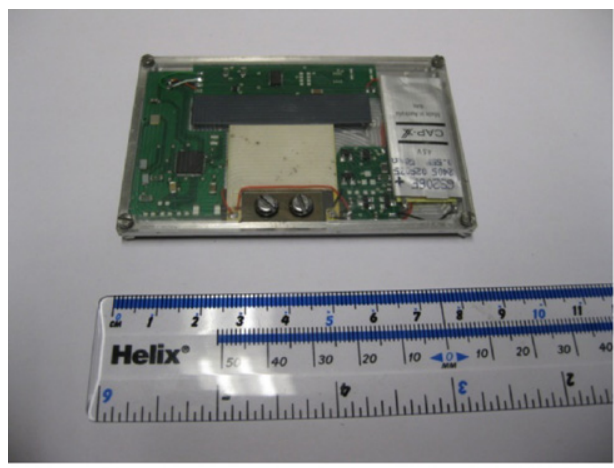

a The smart tag

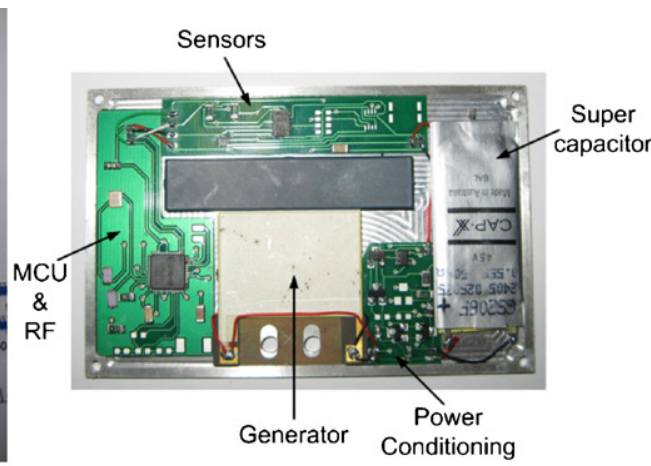

b Layout of the actual device

Fig. 2. Overview of the smart tag. (a) The smart tag. (b) Layout of the actual device. 


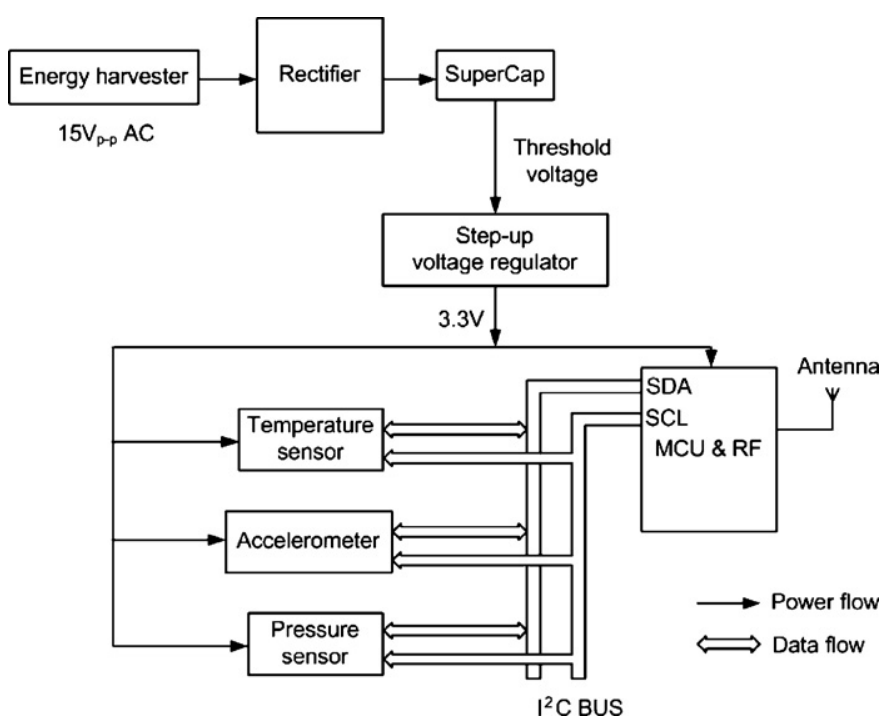

Fig. 3. System flow diagram.

ing space for (a) power conditioning electronics, (b) sensors and (c) the microcontroller with RF components. Fig. 2 shows photos of the actual smart tag with an indication of its dimensions.

\subsection{System description}

Fig. 3 shows the system diagram of the smart tag. The AC voltage generated by the piezoelectric generator is first rectified by a bridge rectifier. P-SPICE simulation shows that the Schottky diode BAT 754 is the most suitable for this application as it offers a low forward voltage drop of $0.2 \mathrm{~V}$. The super-capacitor is charged by the rectified

Table 1

Supply voltage range.

\begin{tabular}{lllll}
\hline & CC2430 & TMP112 & ADXL345 & MPL115A2 \\
\hline Voltage range $(\mathrm{V})$ & $2.1-3.6$ & $1.4-3.6$ & $2-3.6$ & $2.375-5.5$ \\
\hline
\end{tabular}

sure sensor, MPL115A2 from Freescale Semiconductor [26] can all operate at $3.3 \mathrm{~V}$ and have a current consumption of $15 \mu \mathrm{A}, 40 \mu \mathrm{A}$ and $5 \mu \mathrm{A}$, respectively. Table 1 lists the supply voltage range of these components.

\section{Piezoelectric generator}

Due to the size constraints on the smart tag, a bimorph piezoelectric generator is the best energy harvesting solution to this application due to its small thickness. Fig. 4 shows a cross section of the bimorph piezoelectric generator. It is fabricated using screen printing technology, which will be described in this section.

\subsection{T-shape generator}

As an improvement to a previous generator [21], a T-shape cantilever (Fig. 5(b)) is used to replace the conventional cantilever. A T-shape cantilever condenses the proof mass along the direction of the width of the cantilever rather than the direction of the span of the cantilever so that the tip displacement can be reduced to meet the power requirement within the size constraints. Compared to the previous generator, the improved generator has a larger PZT area, thus will generate more power under the same excitation.

A model of the cantilever-based bimorph piezoelectric generator was developed by Roundy et al. [27]. The output voltage, $V$, and power, $P$, of such generators at resonance when two PZT layers are connected in parallel are as follows:

$$
\begin{aligned}
& V(\omega)=\frac{\omega\left(Y_{\mathrm{c}} d_{31} t_{\mathrm{c}} b^{*} / \varepsilon\right)}{\sqrt{\left[\left(\omega_{\mathrm{r}}^{2} / R_{\mathrm{L}} C_{\mathrm{p}}\right)-\left(1 / R_{\mathrm{L}} C_{\mathrm{p}}+2 \zeta \omega_{\mathrm{r}}\right) \omega^{2}\right]^{2}+\omega^{2}\left[\omega_{\mathrm{r}}^{2}\left(1+k^{2}\right)+2 \zeta \omega_{\mathrm{r}} / R_{\mathrm{L}} C_{\mathrm{p}}-\omega^{2}\right]^{2}}} A_{\text {in }} \\
& P(\omega)=\frac{V^{2}(\omega)}{R_{\mathrm{L}}}=\frac{\omega^{2}\left(Y_{\mathrm{c}} d_{31} t_{\mathrm{c}} b^{*} / \varepsilon\right)^{2}}{\left[\omega_{\mathrm{r}}^{2} / R_{\mathrm{L}} C_{\mathrm{p}}-\left(1 / R_{\mathrm{L}} C_{\mathrm{p}}+2 \zeta \omega_{\mathrm{r}}\right) \omega^{2}\right]^{2}+\omega^{2}\left[\omega_{\mathrm{r}}^{2}\left(1+k^{2}\right)+2 \zeta \omega_{\mathrm{r}} / R_{\mathrm{L}} C_{\mathrm{p}}-\omega^{2}\right]^{2}} \cdot \frac{A_{\mathrm{in}}^{2}}{R_{\mathrm{L}}}
\end{aligned}
$$

DC signal. Due to the limitation on the thickness of the smart tag, planar super-capacitors from Cap-XX were chosen as the energy storage device. A super-capacitor of $0.55 \mathrm{~F}$ and $4.5 \mathrm{~V}$ voltage limit was selected to provide an acceptable charging time. This supercapacitor can store a maximum energy of $5.57 \mathrm{~J}$.

To make best use of the power generated by the energy harvester, a step-up voltage regulator, TPS61097 from Texas Instruments [22], has been used. It is able to step up the input voltage from as low as $0.9 \mathrm{~V}$ to a constant output voltage of $3.3 \mathrm{~V}$ which is capable of powering most ICs available on the market. Furthermore, it has efficiency up to $95 \%$ and a typical quiescent current of less than $5 \mu \mathrm{A}$, which makes the system power efficient.

A low power microcontroller (the CC2430 from Texas Instruments (TI) [23]) was selected to provide the microcontroller and RF solution. The CC2430 integrates an 8051 core CPU and an RF transceiver which is compatible with $2.4 \mathrm{GHz}$ IEEE 802.15.4 and ZigBee protocols. Wireless sensor networks of smart tags can be easily built based on the CC2430 platform. Typically, it has a current consumption of $26.9 \mathrm{~mA}$ when the transceiver is active, so has to be duty-cycled in energy constrained applications.

The microcontroller communicates with the sensors via the $\mathrm{I}^{2} \mathrm{C}$ bus. The temperature sensor, TMP 112 from TI [24], the 3-axis accelerometer, ADXL 345 from Analog Devices [25] and the pres- where $Y_{\mathrm{c}}$ is the Young's modulus of the PZT, $t_{\mathrm{c}}$ is the thickness of one PZT layer. $d_{31}$ is strain coefficient in 31 mode. $b^{*}$ is the ratio of strain to vertical displacement. $\varepsilon$ is dielectric constant of the piezoelectric material. $\omega_{\mathrm{r}}$ is the resonant frequency and $\omega$ is the working frequency. $\zeta$ is the damping coefficient. $k$ is the coupling factor. $R_{\mathrm{L}}$ and $C_{\mathrm{p}}$ are the load resistance and the capacitance of the PZT layer, respectively. $A_{\text {in }}$ is the vibration acceleration.

\subsection{Fabrication of the generator}

The generator is fabricated using screen printing alone. This technology was chosen because it is low cost, simple and suitable for batch fabrication. In addition, it does not require photolithography or etching processes.

The substrate material is type $430 \mathrm{~S} 17$ stainless steel which was chosen because it is compatible with the firing temperature required by the screen printable pastes. The substrate thickness is $110 \mu \mathrm{m}$. The screen printing process requires materials to be mixed into a paste form. The lead zirconate titanate (PZT) printable paste used in this work was based upon a piezoelectric ink formed by blending PZT-5H powders of different particle size [28]. The blend of sizes results in an improved film density which, when combined with optimized processing parameters, give a substantially improved $d_{33}$ coefficient of $131 \mathrm{pC} / \mathrm{N}$. In practice, the $d_{31}$ coefficient 


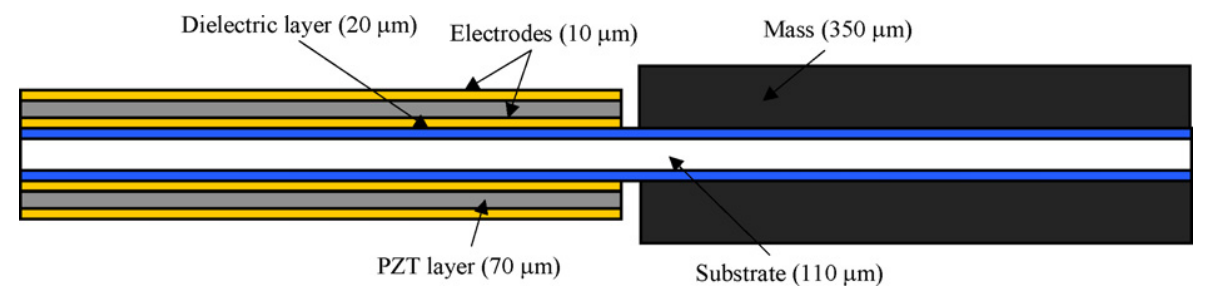

Fig. 4. Cross section through a bimorph piezoelectric generator.

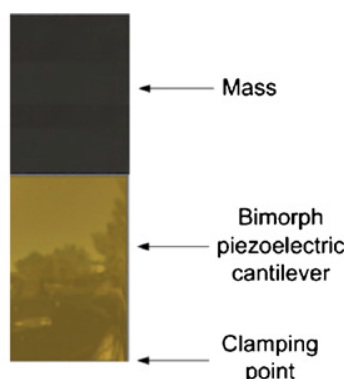

point

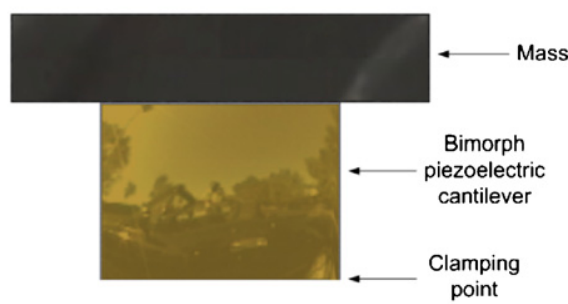

b A T-shape cantilever

Fig. 5. Two types of cantilevers. (a) A conventional cantilever. (b) A T-shape cantilever.

Table 2

Material properties.

\begin{tabular}{|c|c|c|c|c|c|c|}
\hline & Substrate layer & PZT layer & Bottom electrode & Top electrode & Dielectric layer & Mass layer \\
\hline Density $\left(\mathrm{kg} / \mathrm{m}^{3}\right)$ & 7750 & 5440 & 19,280 & 10,500 & 2230 & 9550 \\
\hline Young's modulus (GPa) & 200 & 15 & 80 & 83 & 64 & $\mathrm{~N} / \mathrm{A}$ \\
\hline Poisson's ratio & 0.26 & 0.3 & 0.42 & 0.37 & 0.2 & $\mathrm{~N} / \mathrm{A}$ \\
\hline
\end{tabular}

is difficult to measure. However, it can be assumed to be approximately $-60 \mathrm{pC} / \mathrm{N}$ given the typical $d_{33} / d_{31}$ ratio for PZT materials of -2.2 [29]. Other pastes used in the generators were commercially available and supplied by Electro-Science Laboratories Inc. These were an insulating dielectric (ESL4924), a gold conductor for the bottom electrodes (ESL8836) and a silver polymer paste (ESL1901-S) for the top electrode. A bespoke high density tungsten based printable paste was used to form the inertial mass so that the devices are able to be fabricated completely using the screen printing process [21]. This formulation printed successfully and yielded a film density of $9550 \mathrm{~kg} \mathrm{~m}^{-3}$. Higher density gold or platinum films can easily be printed but the cost of these materials is prohibitive. Table 2 lists properties of the substrate and all the printed films.

The dielectric film was printed first with two separate layers giving a fired film thickness of $20 \mu \mathrm{m}$. The bottom electrode is then printed with a film thickness of $10 \mu \mathrm{m}$. The PZT ink was deposited in two steps giving a film thickness of around $70 \mu \mathrm{m}$. These inks were all dried at $140^{\circ} \mathrm{C}$ and fired at $850^{\circ} \mathrm{C}$ immediately after printing. Next, the polymer top electrode was deposited with one print yielding a film thickness of $10 \mu \mathrm{m}$. A polymer electrode material was chosen as this avoids firing the device at high temperature again. Finally the polymer mass film was printed yielding a mass thickness of around $320 \mu \mathrm{m}$. The finished generators are shown in Fig. 6. The total thickness of the device was around $300 \mu \mathrm{m}$ in the PZT area and $830 \mu \mathrm{m}$ in the mass area. The PZT area is $20 \mathrm{~mm} \times 27 \mathrm{~mm}$ and the mass area is $10 \mathrm{~mm} \times 47 \mathrm{~mm}$. The total mass is around $3.2 \mathrm{~g}$.

Polarisation of the PZT layer was achieved by simultaneously heating the devices and applying an electric field across the top and bottom electrodes. An electric field of $4 \mathrm{MV} \mathrm{m}^{-1}$ was applied and the samples were heated to $200^{\circ} \mathrm{C}$. The field was maintained for $50 \mathrm{~min}$ comprising $30 \mathrm{~min}$ poling at $200^{\circ} \mathrm{C}$ and $20 \mathrm{~min}$ cooling down. If the PZT layer is not polarized properly, performance of the device can be significantly reduced.

\subsection{Experimental results}

\subsubsection{Generator}

As an example, the generator in this case aims to work at a resonant frequency of $67 \mathrm{~Hz}$ and the peak vibration amplitude is $0.4 \mathrm{~g}\left(3.9 \mathrm{~m} \mathrm{~s}^{-2}\right)$, i.e., $0.29 g_{\text {RMS }}\left(2.8 \mathrm{~m} \mathrm{~s}^{-2}\right)$, which coincides with the peak vibration taken from a PZL SW4 helicopter during flight [21]. Dimensions of the generator may vary according to the specific application.

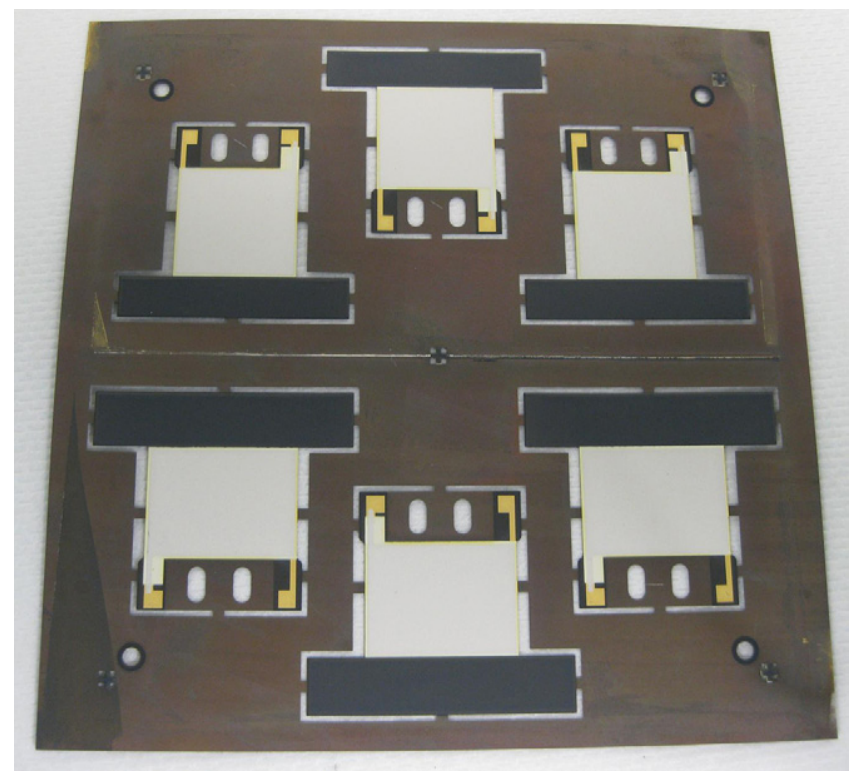

Fig. 6. Screen printed T-shape piezoelectric generator. 


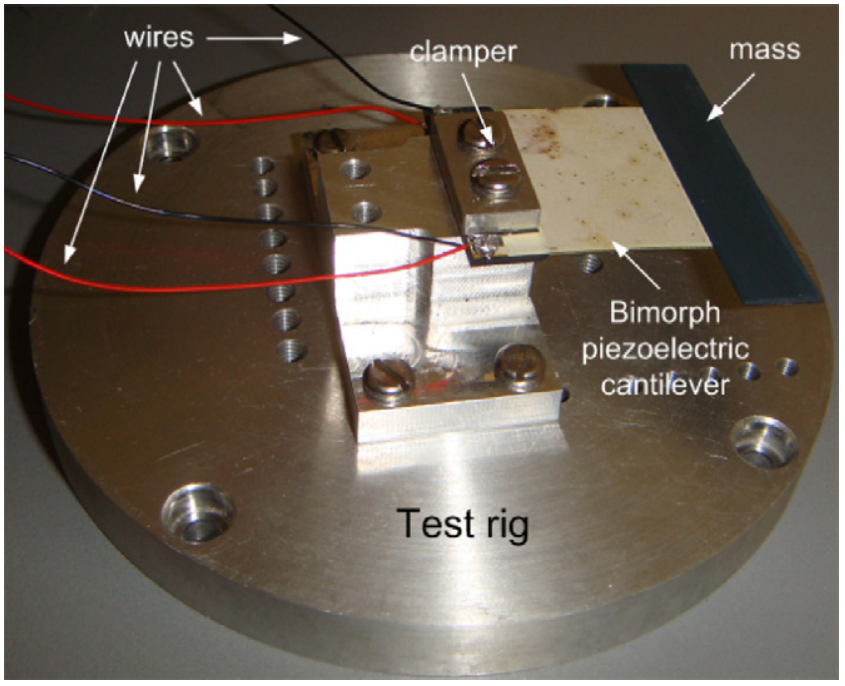

Fig. 7. The generator on the test rig.

The generator was tested on a shaker (Labworks ET-126) with a programmable resistance box and a PC with LabVIEW software collecting the data. Fig. 7 shows the generator was clamped on the test rig.

Fig. 8 shows the experimental RMS open circuit output voltage and output power at the optimum resistive load of $57 \mathrm{k} \Omega$ when the two PZT layers were connected in parallel. The generator was able to generate the maximum RMS output power of $240 \mu \mathrm{W}$ at the resonant frequency of $66.2 \mathrm{~Hz}$. The resonant frequencies are $0.8 \mathrm{~Hz}$ or $1.2 \%$ off the target frequency. Compared to the previously reported generator [21], the output power has been doubled at a $60 \%$ lower excitation. The latest generator has a power density of $600 \mu \mathrm{W} / g_{\mathrm{pk}}$ while the power density of the previous one is $118 \mu \mathrm{W} / g_{\mathrm{pk}}$. The performance of the generator agrees with the theoretical analysis as in Eqs. (1) and (2).

\subsubsection{Power conditioning circuit}

The voltage across the super-capacitor was charged by the piezoelectric generator via a bridge rectifier. Ideally, the input impedance of the power conditioning circuit should match the optimum load mentioned in the previous section to achieve the maximum energy transfer. However, due to the size of the supercapacitor, input impedance of the power conditioning circuit
Table 3

Practical power input to the super capacitor

\begin{tabular}{ll}
\hline Voltage across the super capacitor $(\mathrm{V})$ & Charging power $(\mu \mathrm{W})$ \\
\hline 0 & 95 \\
0.5 & 25 \\
1 & 33 \\
1.5 & 40 \\
2 & 48 \\
2.5 & 52 \\
3 & 52 \\
3.5 & 50 \\
\hline
\end{tabular}

varies with the voltage across the super-capacitor. This makes impedance matching more difficult, which will be the study of future work. Here we limit ourselves to more simple power conditioning circuitry to demonstrate the feasibility of this more common approach.

As mentioned in Section 2.2, a step-up voltage regulator TPS61097 was evaluated to determine if it enabled the system to start working at a lower super-capacitor voltage. Before this could be done, however, it was experimentally found that, if the input of the voltage regulator was directly connected to the super-capacitor (see Fig. 9(a)), the regulator tried to operate before the input voltage reached the specified minimum of $0.9 \mathrm{~V}$, resulting in the regulator sinking current from the super-capacitor at a rate that increased with applied voltage. As a result, the voltage of the super-capacitor stops increasing beyond $0.5 \mathrm{~V}$ (it needs to get to $0.9 \mathrm{~V}$ for guaranteed operation of the regulator) with the result that the regulator can never switch on properly. Consequently, the voltage regulator can never achieve the target voltage of $3.3 \mathrm{~V}$ as shown in Fig. 9(b). Thus, the system cannot be activated.

To overcome this drawback, a cold start circuit [5] was introduced. It consists of a low power voltage detector Torex XC61C (power consumption around $1.4 \mu \mathrm{W}$ ) with a specified switching voltage of $2 \mathrm{~V}$ and an $\mathrm{N}$-channel MOSFET ZXMN2B01F as shown in Fig. 10(a) and (b). The voltage regulator is disconnected at the ground node and starts working only when the super-capacitor voltage reaches $2 \mathrm{~V}$. In addition, due to the hysteresis in the switching value of Torex XC61C, it will not immediately turn off when the super-capacitor voltage temporarily drops below 2 V. Fig. 10(c) shows the experimental results of the modified power conditioning circuit. It was found that when the super-capacitor voltage reached $2 \mathrm{~V}$, the step-up voltage regulator successfully turned on and achieved $3.3 \mathrm{~V}$.

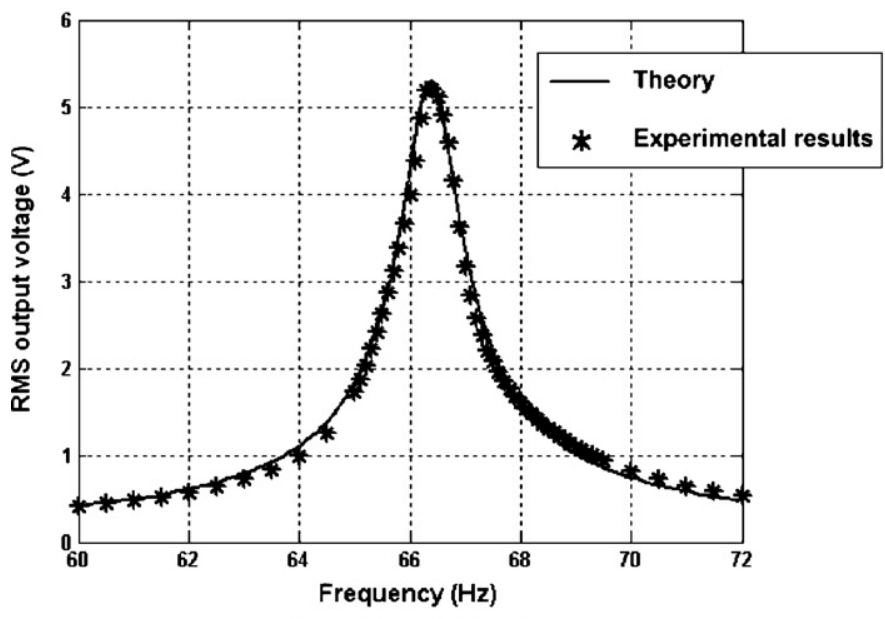

a Open circuit RMS voltage

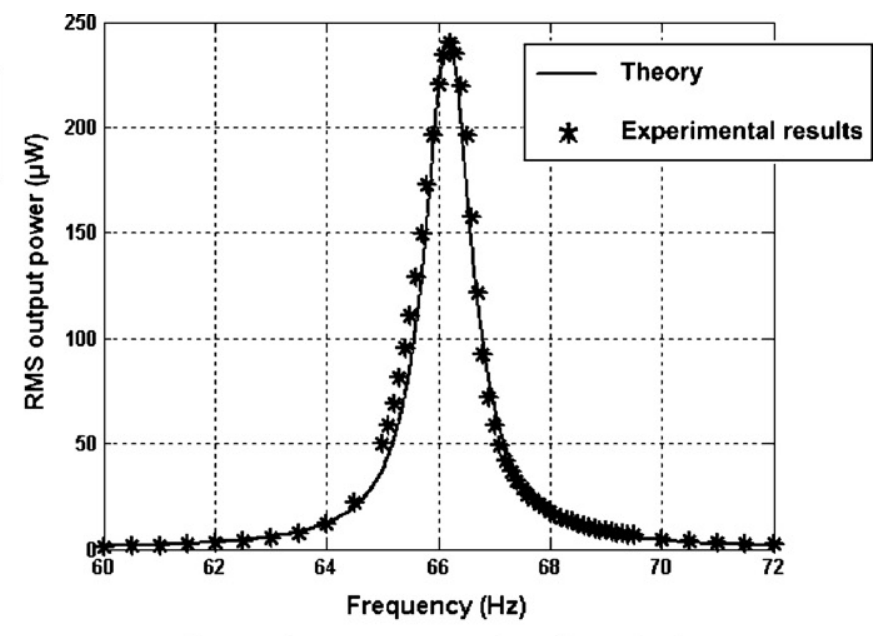

b RMS output power at the optimum load

Fig. 8. Performance of generators. (a) Open circuit RMS voltage. (b) RMS output power at the optimum load. 


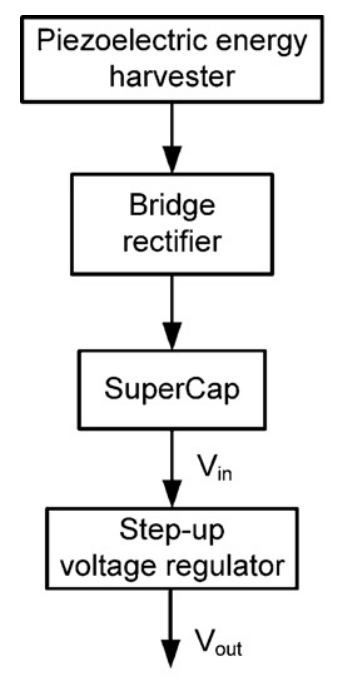

a Block diagram

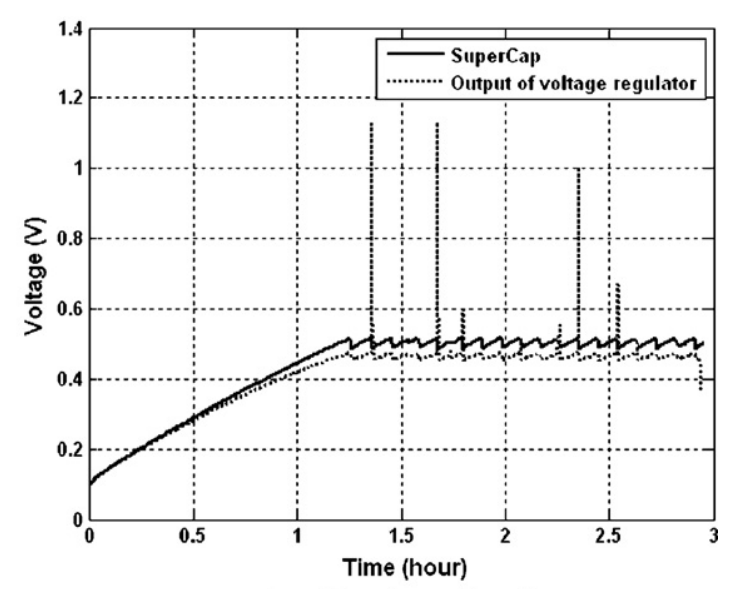

b Experimental results

Fig. 9. Case 1: the voltage regulator was directly connected to the super-capacitor. (a) Block diagram. (b) Experimental results.

Table 3 lists the practical power input to the super capacitor at various voltages across the super capacitor when no voltage regulator is connected. It was found that the practical power input to the super capacitor is low compared to the measured power in an opti- mum resistive load. There are two reasons for this. First, there is no impedance matching mechanism involved in this application and thus the practical power input to the super capacitor is not the optimum output of the energy harvester. Although using autonomous

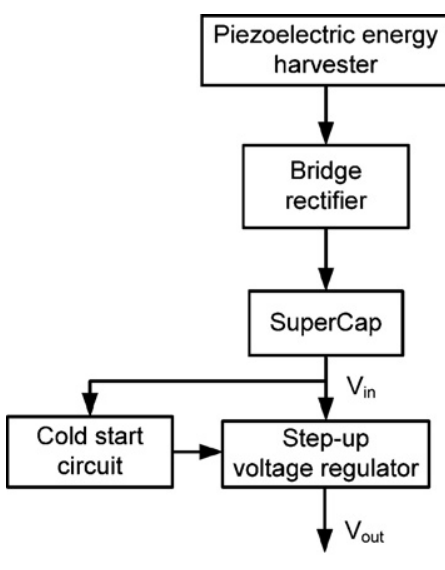

a Block diagram

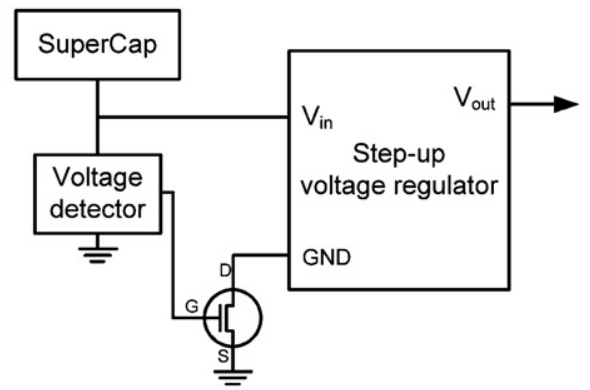

b Cold start circuit

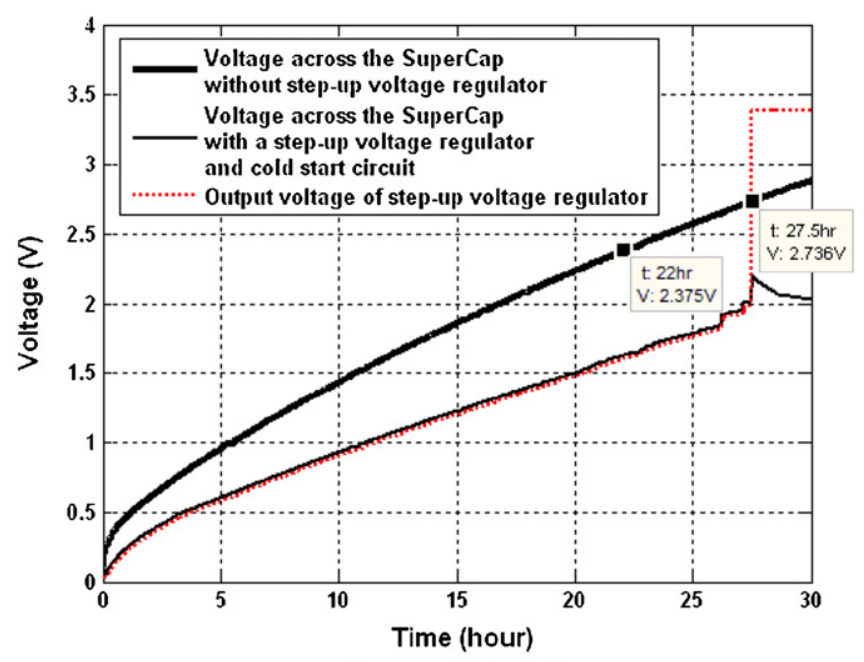

c Experimental results

Fig. 10. Case 2: the voltage regulator was turned on by a cold start circuit. (a) Block diagram. (b) Cold start circuit. (c) Experimental results. 


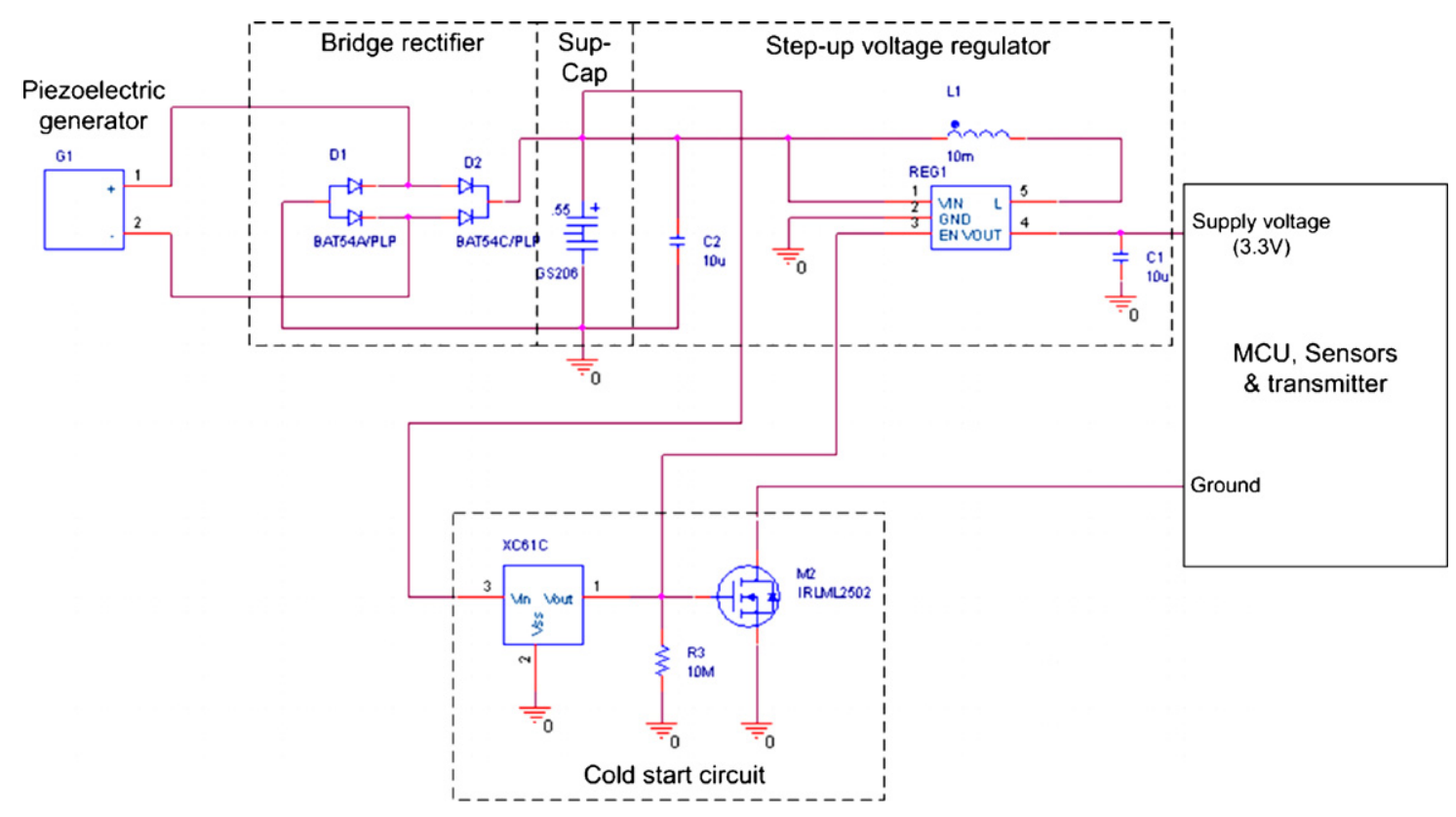

Fig. 11. Test circuit.

impedance matching circuits can improve the efficiency of power conditioning circuits [30-32], high power consumption in these circuits makes them not possible or sensible in applications where energy harvester produces output of hundreds of microwatts, as discussed in this paper. Second, it is worth mentioning that when the voltage across the super capacitor changes, the electrical load and thus electrical damping also change. This causes the resonant frequency of the energy harvester to vary slightly, which means that the energy harvester does not always work at resonance when charging a super capacitor.

As listed in Table 1, the minimum supply voltage to enable the microprocessor system to work is $2.375 \mathrm{~V}$ and so in principle the system could be powered direct from the super-capacitor. An experiment was carried out to measure the influence of the step-up regulator by measuring the time taken to reach the minimum supply voltage with and without the regulator. Without the step-up voltage regulator, it took $22 \mathrm{~h}$ to charge the super-capacitor from zero to the minimum supply voltage required for the system to work. However, with the step-up voltage regulator, it took $27.5 \mathrm{~h}$ to charge the super-capacitor from zero to the $2 \mathrm{~V}$ needed to turn on the step-up regulator to start the system. This means that some current leakage occurred in this circuit as shown in Fig. 10(c). However, a voltage regulator can enable the system to work when the super-capacitor voltage is lower than $2.375 \mathrm{~V}$, and gives the option to utilize the capacity in the capacitor from $0.9 \mathrm{~V}$ (where the regulator stops working) to $2 \mathrm{~V}$ (initial turn-on) by including an 'ENABLE' option by controlling the gate of the FET by a microprocessor $\mathrm{I} / \mathrm{O}$ line. Therefore, the circuit diagram shown in Fig. 10(a) was selected.

\section{Performance of the system}

One of the most important characteristics of a self-powered system is its waiting time which is defined as the period in which the system accumulates enough energy to perform one measurement and wireless data transmission (termed 'one task'). The waiting time of the system powered by the circuit as shown in Fig. 11 was investigated experimentally and was discussed.

The super-capacitor was charged by the piezoelectric generator via a bridge rectifier. A voltage detector was used to monitor the voltage across the super-capacitor. When the voltage across the super-capacitor was below the preset voltage, the voltage detector output 'low', thus the step-up voltage regulator was disabled and the system was off. Once the preset voltage was reached, the voltage detector switched 'high', which enabled the voltage regulator and connected the system ground so that the system was activated.

When the system was activated, the microcontroller turned on only some basic functions to allow sensors to measure and transmit the data to the microcontroller. Once the measurement data was received, it then switched on the RF transmitter to wirelessly transmit data to the base station and then the microcontroller was switched to sleep mode and waited to be activated.

Fig. 12 shows the waiting time of the system with variation of voltage across the super-capacitor when the system is activated (termed 'starting voltage'). It was found that the waiting time decreases with the increase of the starting voltage when the starting voltage is lower than $1.7 \mathrm{~V}$. The reason for this is that the voltage regulator has lower efficiency when its input voltage, i.e., starting voltage, is low $(<90 \%)$ [22]. When the input voltage of the voltage regulator, i.e., starting voltage, is over $1.7 \mathrm{~V}$, the efficiency of the

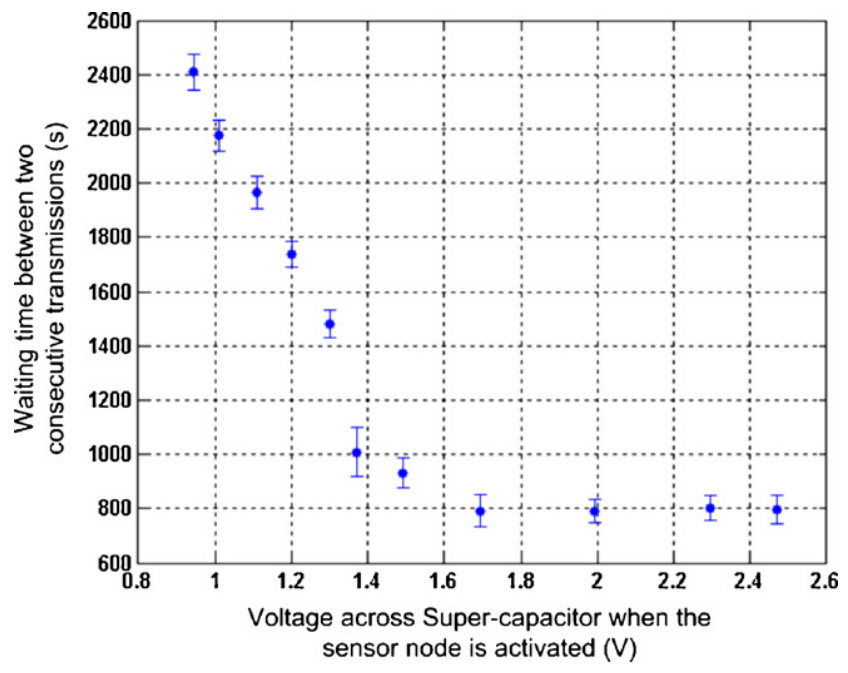

Fig. 12. Waiting time with variation of starting voltage. 


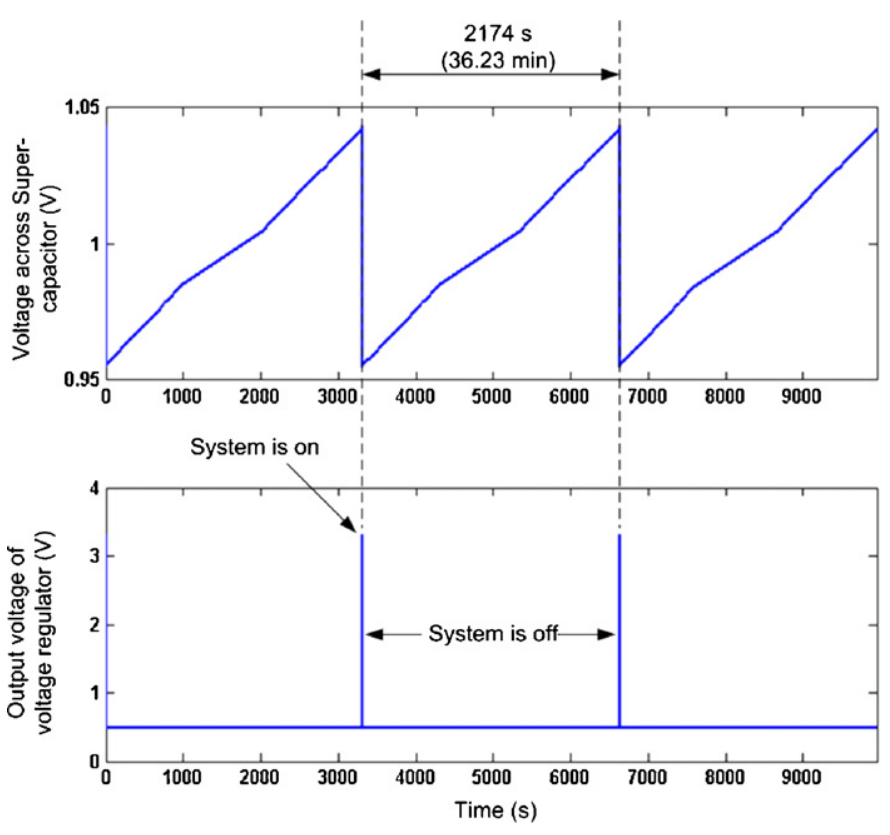

Fig. 13. Time sequence of the system (starting voltage = $1 \mathrm{~V}$ ).

voltage regulator is between $93 \%$ and $95 \%$. Thus, the waiting time of the system did not change appreciably when the starting voltage was over $1.7 \mathrm{~V}$. Therefore, the starting voltage of the system is preferred to be over $1.7 \mathrm{~V}$.

Figs. 13 and 14 show time sequence of the system when the starting voltage is $1 \mathrm{~V}$ and $2 \mathrm{~V}$, respectively. It is found in the test that the overall operating time for the system to finish measurement and transmission of data is $284 \mathrm{~ms}$ in which 90 bits of data is transmitted (shown in Fig. 15).

\section{Conclusions and future work}

This paper highlights the development of a self-powered lowprofile wireless sensing device (smart tag). The smart tag has dimensions of a credit card and can be easily integrated into any

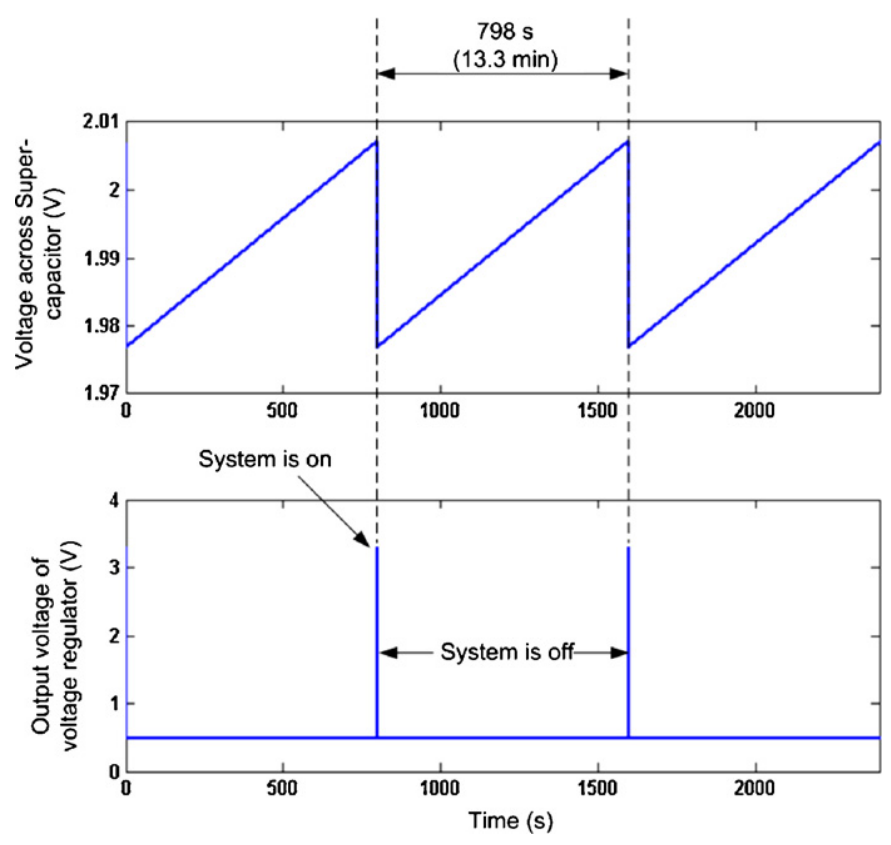

Fig. 14. Time sequence of the system (starting voltage $=2 \mathrm{~V}$ ).

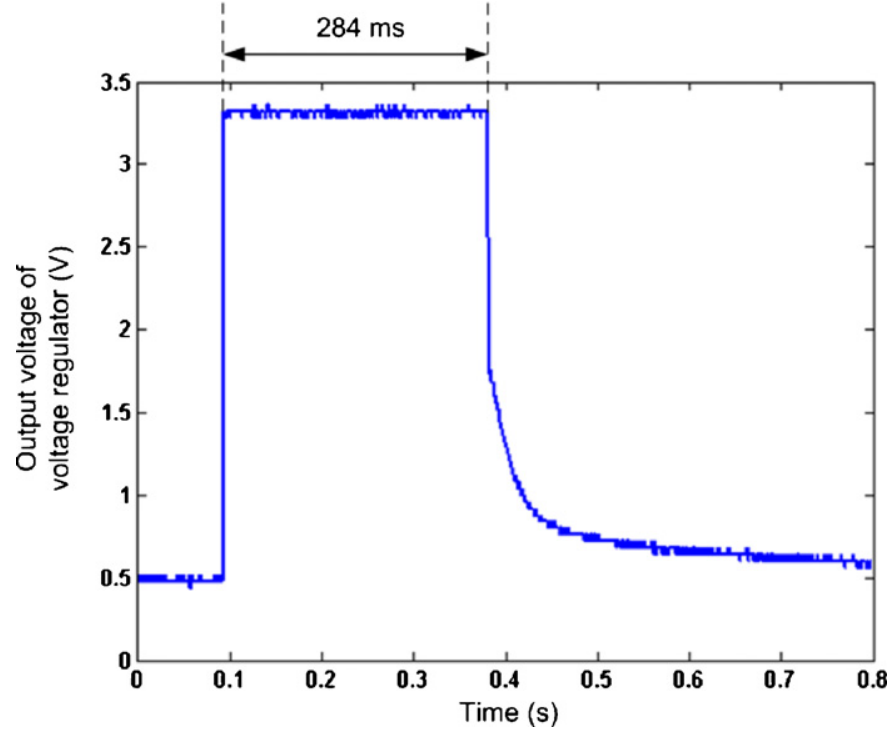

Fig. 15. Output voltage of the voltage regulator when the system is on.

application. It consists of a microcontroller with RF components, an accelerometer, a temperature sensor and a pressure sensor. All components are powered by a super-capacitor that is charged by a thick film bimorph piezoelectric generator. According to specific applications, various thick film bimorph piezoelectric generators can be designed and fit into the smart tag.

A novel type of T-shape bimorph piezoelectric generator has been designed and fabricated. As an example, the generator was designed to suit the target vibration with the frequency of $67 \mathrm{~Hz}$ and the peak amplitude of $0.4 \mathrm{~g}\left(3.9 \mathrm{~m} \mathrm{~s}^{-2}\right)$, which coincides with the peak vibration taken from a helicopter during flight. Experimentally, the proposed generator can produce a maximum output power of $240 \mu \mathrm{W}$ when connected to the optimum resistive load of $57 \mathrm{k} \Omega$ and excited at the target vibration. The experimental results were found to agree with the model of the bimorph piezoelectric generator previously developed by Roundy.

In addition, two power conditioning circuits have been tested. It was found that if the input of the voltage regulator was directly connected to the super-capacitor, the voltage of the super-capacitor would stop increasing beyond $0.5 \mathrm{~V}$ and the voltage regulator can never output target voltage, which means that system can never work. A cold start circuit was then introduced to solve this problem. The test results showed that the step-up voltage regulator can successfully turn on and provide $3.3 \mathrm{~V}$ when the super-capacitor voltage reached $2 \mathrm{~V}$. However, the time for the generator to charge the super-capacitor from zero to the voltage that turns on the stepup regulator to start the system is longer than the time for the generator to charge the super-capacitor from zero to the minimum supply voltage to start the system. Nevertheless, circuit with a voltage regulator is preferred because it enables the system to work at a lower super capacitor voltage.

It was found that waiting time of the system is much longer when the starting voltage is lower than $1.7 \mathrm{~V}$. This is due to low efficiency of the voltage regulator at its input voltages lower than $1.7 \mathrm{~V}$. When the starting voltage is over $1.7 \mathrm{~V}$, waiting time of the system is around $800 \mathrm{~s}$. Therefore, it is preferred that the system is only turned on when the voltage across the super-capacitor is over $1.7 \mathrm{~V}$.

Future work includes optimizing the power conditioning circuit to shorten the time that is needed for the generator to charge the super-capacitor to provide the minimum supply voltage to start the system. Some possible solutions are to use a super-capacitor with a smaller capacitance and choose a more suitable voltage regulator 
for this particular application. In addition circuit modifications will be investigated to allow better use of the charge within the capacitor as any charge in the capacitor when the terminal voltage is less than the regulator switch-on voltage is currently unavailable. There are some autonomous impedance matching mechanisms [30-32] that have been reported to improve efficiency of power conditioning circuits. However, all these methods require additional control and thus energy. Although these methods are able to increase efficiency of the system, power consumption in the additional control circuits makes it not practical for low power generators of the order of a few hundred microwatts at the current state of development. More effort will be made to improve existing power conditioning methods for practical applications. Furthermore, the test set up is currently being modified in order to replicate actual application vibrations. The smart tag will be tested in this manner to observe its behaviour. However, it has been demonstrated that thick-film piezoelectric generators can be used to power conventional 'off the shelf low power sensor systems relatively straightforwardly, thus opening up new areas of application for such energy scavengers.

\section{Acknowledgement}

This work has been funded under the EU Framework 7 project TRIADE (212859).

\section{References}

[1] I.F. Akyildiz, W. Su, Y. Sankarasubramaniam, E. Cayirci, Wireless sensor networks: a survey, Computer Networks 38 (4) (2002) 393-422.

[2] S.P. Beeby, M.J. Tudor, N.M. White, Energy harvesting vibration sources for microsystems applications, Measurement Science and Technology 17 (2006) 175-195.

[3] D. Zhu, M.J. Tudor, S.P. Beeby, Strategies for increasing the operating frequency range of vibration energy harvesters: a review, Measurement Science and Technology 21 (2) (2010) 022001.

[4] S. Roundy, P.K. Wright, J. Rabaey, A study of low level vibrations as a power source for wireless sensor nodes, Computer Communications 26 (11) (2003) 1131-1144.

[5] E. Lefeuvre, A. Badel, C. Richard, D. Guyomar, A comparison between several vibration-powered piezoelectric generators for standalone systems, Sensors and Actuators A: Physical 126 (2006) 405-416.

[6] S.R. Anton, H.A. Sodano, A review of power harvesting using piezoelectric materials (2003-2006), Smart Materials and Structures 16 (2007) 1-21.

[7] S. Priya, D. Inman, Energy Harvesting Technologies, Springer, 2009.

[8] E.P. James, M.J. Tudor, S.P. Beeby, N.R. Harris, P. Glynne-Jones, J.N. Ross, N.M. White, An investigation of self-powered systems for condition monitoring applications, Sensors and Actuators A: Physical 110 (2004) 171-176.

[9] R. Torah, P. Glynne-Jones, J. Tudor, T. O’Donnell, S. Roy, S. Beeby, Self-powered autonomous wireless sensor node using vibration energy harvesting, Measurement Science and Technology 19 (12) (2008) 125202.

[10] C. Boller, Ways and options for aircraft structural health management, Smart Materials and Structures 10 (2001) 432-440.

[11] D.J. Inman, M. Ahmadian, R.O. Claus, Simultaneous active damping and health monitoring of aircraft panels, Journal of Intelligent Material Systems and Structures 12 (2001) 775-783.

[12] B.D. Larder, Assessing the benefit of helicopter health and usage monitoring systems, in: IEE Seminar on Aircraft Airborne Condition Monitoring, Gloucester, UK, 14th May 2003, 2003, pp. 6/1-6/6.

[13] D. Montalvão, N.M.M. Maia, A.M.R. Ribeiro, A review of vibration-based structural health monitoring with special emphasis on composite materials, Shock and Vibration Digest 38 (4) (2006) 130.

[14] T. Monnier, Lamb waves-based impact damage monitoring of a stiffened aircraft panel using piezoelectric transducers, Journal of Intelligent Material Systems and Structures 17 (5) (2006) 411-421.

[15] M. Lallart, T. Monnier, D. Guyomar, Energy efficient method for embedded insitu structural health monitoring, Journal of Structural Health Monitoring 9 (2010) 87-98.

[16] N. Elvin, A. Elvin, D.H. Choi, A self-powered damage detection sensor, Journal of Strain Analysis 38 (2003) 115-124.
[17] S.C. Galea, S. Velden, I. Powlesland, Q. Nguyen, P. Ferrarotto, M. Konak, Flight demonstrator of a self-powered SHM system on a composite bonded patch attached to an F/A-18 aileron hinge, in: Asia-Pacific Workshop on Structural Health Monitoring, Yokohama, Japan, 2006.

[18] B.L. Grisso, Advancing Autonomous Structural Health Monitoring, PhD thesis, Virginia Polytechnic Institute (2007).

[19] M. Lallart, D. Guyomar, Y. Jayet, L. Petit, E. Lefeuvre, T. Monnier, P. Guy, C. Richard, Synchronized switch harvesting applied to selfpowered smart systems: piezoactive microgenerators for autonomous wireless receiver, Sensors and Actuators A: Physical 147 (1) (2008) 263-272.

[20] TRIADE website, 2010, http://triade.wscrp.com/Cited (accessed 26.10.10).

[21] M. Stamos, C. Nicoleau, R. Torah, J. Tudor, N.R. Harris, A. Niewiadomski, S.P. Beeby, Screen-printed piezoelectric generator for helicopter health and usage monitoring systems, in: Proceedings of PowerMEMS 2008, Sendai, Japan, 9-12th November 2008, 2008.

[22] TPS61097 datasheet, 2010, http://focus.ti.com/docs/prod/folders/print/ tps61097-33.html (accessed 26.10.10).

[23] CC2430 datasheet, 2010, http://focus.ti.com/docs/prod/folders/print/ cc2430.html (accessed 26.10.10).

[24] TMP112 datasheet, 2010, http://focus.ti.com/docs/prod/folders/print/ tmp112.html (accessed 26.10.10).

[25] ADXL345 datasheet, 2010, http://www.analog.com/en/sensors/inertialsensors/ adxl345/products/product.html (accessed 26.10.10).

[26] MPL115 datasheet, 2010, http://www.freescale.com/webapp/sps/site/prod summary.jsp? code=MPL115A\&nodeI d=01126990366B26 (accessed 26.10.10).

[27] S. Roundy, P.H. Wright, J.M. Rabaey, Energy scavenging for wireless sensor networks with special focus on vibrations, Kluwer Academic Publishers, Norwell, MA 02061, USA, 2004.

[28] R.N. Torah, S.P. Beeby, M.J. Tudor, N.M. White, Thick-film piezoceramics and devices, Journal of Electroceramics 19 (1) (2007) 97-112.

[29] R. Torah, Optimisation of the piezoelectric properties of thick-film piezoceramic devices, PhD Thesis, University of Southampton (2004).

[30] G.K. Ottman, H.F. Hofmann, G.A. Lesieutre, Optimized piezoelectric energy harvesting circuit using step-down converter in discontinuous conduction mode, IEEE Transactions on Power Electronics 18 (2003) 696-703.

[31] E. Lefeuvre, D. Audigier, C. Richard, D. Guyomar, Buck-boost converter for sensorless power optimization of piezoelectric energy harvester, IEEE Transactions on Power Electronics 22 (2007) 2018-2025.

[32] M. Lallart, D.J. Inman, Low-cost integrable tuning-free converter for piezoelectric energy harvesting optimization, IEEE Transactions on Power Electronics 25 (2010) 1811-1819.

\section{Biographies}

D. Zhu obtained a BEng in Information and Control Engineering from Shanghai Jiao Tong University, China, in 2004. He was awarded his MSc and PhD in University of Southampton, UK in 2005 and 2009, respectively. He is currently a research fellow in Electronic Systems and Devices Group, School of Electronics and Computer Science, University of Southampton, UK.

M.J. Tudor obtained a BSc (Eng) in electronic and electrical engineering from University College London and a PhD in physics from Surrey University. In 1987, John joined Schlumberger Industries working first at their Transducer Division in Farnborough and then their Research Centre in Paris, France. In 1990, he joined the University of Southampton as a lecturer and his research interests covered optical fibre sensors and micromachined sensors. In 1994, John moved to ERA Technology becoming the microsystems program manager. In 2001, John returned to the School of Electronics and Computer Science, University of Southampton to pursue university based research in microsystems. John is currently a principal research fellow. He has over 70 publications and is both a chartered physicist and engineer.

S.P. Beeby obtained his BEng (Hons) in mechanical engineering in 1992 and was awarded his PhD in 1998. He is currently a reader in the School of Electronics and Computer Science and is researching in the field of micro-electro-mechanical systems (MEMS). In particular, his research involves the development of fabrication processes whereby thick-film piezoelectric materials can be combined with micromachined silicon structures. His skills include the finite element modelling and design of MEMS devices, silicon processing and MEMS packaging, and testing. He currently has over 150 publications in the field.

N.R. Harris is a lecturer based in the electronics and computer science department at Southampton. He graduated in 1988 from the University of Bath and was awarded a $\mathrm{PhD}$ in 1997 from the University of Southampton, on the use of ultrasound for communication purposes. His research interests include thick-film sensors, ultrasonic particle manipulation in microfluidic systems, and wireless sensor networks. He is a member of the IEE and a chartered engineer. 